\title{
IDENTIDADE DOCENTE: PERCEPC̣ÕES DE PROFESSORES DE BIOLOGIA INICIANTES
}

\author{
CAROLINA KIYOKO MELLINI ${ }^{*}$ \\ https://orcid.org/0000-0002-4913-4507 \\ DANIEL FERNANDO BOVOLENTA OVIGLII"* \\ https://orcid.org/0000-0002-4057-547X
}

RESUMO: Este texto apresenta um estudo acerca da constituição da identidade profissional de professores de Biologia que estão no início de suas carreiras. Para o desenvolvimento da pesquisa foram realizadas entrevistas semiestruturadas com quatro professores egressos do curso de Licenciatura em Ciências Biológicas oferecido por uma instituição pública federal de educação superior, que estão em exercício docente. As informações levantadas foram interpretadas à luz da Análise Textual Discursiva e apontam: (i) que a identidade profissional é construída a partir das relações sociais e que a identificação com a profissão durante a formação inicial está relacionada com a intenção do aluno, logo nos primeiros anos da faculdade, em seguir a carreira docente ou não; (ii) que os saberes docentes são elementos que fazem parte da identidade do professor e que o Estágio Curricular Supervisionado e programas de iniciação à docência são de suma importância na formação do professor.

Palavras-chave: Identidade Docente. Saberes Docentes. Professor de Biologia.

\section{IDENTIDAD DOCENTE: PERCEPCIONES DE PROFESORES PRINCIPIANTES DE BIOLOGÍA}

RESUMEN: Este artículo presenta un estudio sobre la constitución de la identidad profesional de los profesores de Biología que están en el inicio de sus trayectorias profesionales. Para el desarrollo de la investigación se realizaron entrevistas semiestructuradas con cuatro docentes graduados en Formación del Profesorado en

\footnotetext{
* Mestra em Educação pela Universidade Federal do Triângulo Mineiro (UFTM). Membro do Grupo de Estudo e Pesquisa em Espaços Não Formais e Ensino de Ciências (GENFEC).

E-mail:<carolmellini@hotmail.com>.

* * Doutor em Educação para a Ciência pela Universidade Estadual Paulista Júlio de Mesquita Filho (UNESP).

Professor do Departamento de Educação em Ciências, Matemática e Tecnologias (DECMT) da Universidade Federal do Triângulo Mineiro (UFTM).

E-mail:<daniel.ovigli@uftm.edu.br >.
}

\footnotetext{
' Universidade Federal do Triângulo Mineiro, Uberaba, MG - Brasil.

" Universidade Federal do Triângulo Mineiro, Departamento de Educação em Ciências, Matemática e Tecnologias, Uberaba, MG · Brasil.
} 
Ciencias Biológicas de una institución pública de educación superior, que imparten clases. Los datos se interpretaron a la luz de la teoría del Análisis Textual Discursivo y señalan: (i) que la identidad profesional se construye a partir de las relaciones sociales y que la identificación con la profesión durante la formación inicial está relacionada con la intención del estudiante, aún en los primeros años de universidad, de seguir la trayectoria docente o no; (ii) que los saberes docentes son elementos que forman parte de la identidad del maestro y que la Pasantía Curricular Supervisada así como los programas de iniciación a la enseñanza son de gran importancia en la formación del profesor. Palabras clave: Identidad docente. Saberes docentes. Profesor de Biología.

\section{TEACHING IDENTITY: PERCEPTIONS OF BEGINNING TEACHERS OF BIOLOGY}

ABSTRACT: This text presents a study about the constitution of the professional identity of Biology teachers who are at the beginning of their careers. For this research, semi-structured interviews were carried out with four teachers graduated from the Biological Sciences undergraduate course offered by a public higher education institution, who are teaching. The data were interpreted in the light of the Discursive Textual Analysis theory and point out: (i) that professional identity is built on social relations and that identification with the profession during initial education is related to the student's intention to pursue the teaching career in the early years of college or not; (ii) that teaching knowledges are elements that are part of the teacher's identity and that Supervised Curricular Internship and teacher initiation programs have a great importance in teacher education. Keywords: Teaching Identity. Teaching Knowledge. Biology Teacher. 


\section{INTRODUÇÃO}

Compreender de que modo o docente constrói sua identidade profissional demanda compreender também como ele estabelece suas relações com a profissão e como se constitui no percurso profissional o "ser professor", revelando suas maneiras de ser e de tornar-se professor.

A constituição da identidade profissional é resultante de sucessivos processos de socialização. Segundo Schaffel (2007), a socialização é um processo de relação, de identificação, depertencimento a um grupo, istoé, socializar-seéassumirindividualmente os comportamentos e as atitudes de um grupo o qual, inconscientemente, acaba por condicionar as condutas, os desejos e as preferências individuais.

As vivências, experiências e representações produzidas ao longo da história de vida do indivíduo possuem implicações na maneira com que ele irá pensar e desenvolver a docência em sua carreira (SOUZA, 2012). A formação acadêmica possui grande influência na construção da identidade docente, o curso superior garante a formação do professor, mas não garante que ele se torne professor (GERALDI, 2010). Ou seja, a formação inicial não consegue construir a identidade do profissional isoladamente, esta identidade está em constante construção e será constituída pela formação inicial, pela formação continuada e também pela prática - além das vivências do indivíduo antes de iniciar sua formação específica.

Identidade e Saberes Docentes são temáticas que estão diretamente relacionadas. Da mesma forma que a identidade vai sendo construída a partir de relações sociais, de vivências e experiências ao longo da trajetória do professor, é assim também com os saberes. Segundo Tardif (2010), as vivências anteriores dos indivíduos (antes de iniciarem o curso de formação) constituem um fator marcante na construção da identidade profissional. Os saberes envolvem os professores ao longo de toda a sua vida profissional, desde a sua formação acadêmica até as formações paralelas às instituições educacionais (incluindo aqui as formações sociais e culturais). Adotamos neste estudo a perspectiva de saberes docentes proposta por Tardif (2002), contemplando quatro diferentes categorias de saberes: Saberes da Formação Profissional, Saberes Disciplinares, Saberes Curriculares e Saberes Experienciais.

Com a finalidade de contribuir para as discussões e reflexões acerca das temáticas identidade e saberes docentes, nos propomos a investigar de que forma essa identidade docente é construída e quais elementos a compõem - o que nos fornece subsídios que revelam quem é esse professor. Assim, esse estudo teve como objetivo principal compreender, a partir das percepções de quatro egressos de um curso de Licenciatura em Ciências Biológicas oferecido por Instituição de Ensino Superior (IES) pública federal, como se constitui a identidade profissional docente em relação aos saberes destes professores.

\section{A CONSTRUC̣ÃO SOCIAL DA IDENTIDADE E OS SABERES DOCENTES}

Normalmente o termo "identidade" é utilizado para caracterizar como cada indivíduo se vê e é visto pelos outros. Esse ponto de vista sobre si está presente durante a vida toda e nos ambientes em que o indivíduo participa. A temática "identidade" tem sido amplamente discutida em várias áreas do conhecimento das 
Ciências Humanas e Sociais, como indicam os trabalhos de Ciampa (1998), Brown e Starkey (2000) e Dubar (2005), por exemplo.

A construção identitária do professor corresponde a um processo envolvendo constantes socializações. Segundo Dubar (2005), socializar-se é assumir o sentimento de pertencimento a um determinado grupo adotando, assim, de modo individual, as atitudes, bem como os comportamentos do grupo ao qual o indivíduo deseja pertencer e ser reconhecido. A identidade, portanto, é construída segundo a influência de um determinado contexto histórico/cultural (e social!) no qual o docente se desenvolve profissionalmente, por meio da interação entre a dimensão subjetiva (que corresponde à imagem que tem de si mesmo) e a dimensão objetiva (que corresponde à imagem que o outro tem ou espera de você). Estes universos (subjetivo e objetivo) são confrontados no processo de socialização, no qual o profissionalismo adquire influência importante na construção desta identidade.

Da mesma forma, Ciampa (1998) define a identidade humana como uma metamorfose, que se constitui de recíproca subjetividade e objetividade, não se tratando apenas de um processo natural, mas de um processo histórico e social, que se realiza essencialmente como produção de sentido. Isto significa que o ser humano não constrói sua identidade sozinho, ele depende do juízo dos outros, bem como de suas próprias orientações e autodefinições (DUBAR, 2005).

A identidade não é imutável, ela é decorrente de um processo de transformações, vinculada à época histórica e ao contexto social na qual o indivíduo está imerso. Conforme Dubar (2005), os processos de socialização têm início logo que o indivíduo nasce e passa a receber certos aspectos identitários como, por exemplo, nome, sobrenome, gênero e nacionalidade. Apesar de aparentar constituir aspectos definitivos, essas formas identitárias podem ser alteradas no futuro: o indivíduo, quando adulto, pode mudar seu nome/sobrenome, sua nacionalidade ou mesmo assumir outra orientação sexual; assim, esses aspectos representam uma identidade provisória.

O indivíduo ao longo de sua vida vai formando relações com diversas pessoas e instituições, apropriando-se ou não daquilo que os outros lhe apresentam ou dizem que ele é. Essas relações, em algum momento, influenciarão seus modos de ser e de pensar (DUBAR, 2005). Dessa forma, a identidade se caracteriza como um processo de mudança e de alteridade em que os "[...] papéis sociais assumidos vão sendo tecidos de acordo com os contextos sociais, podem ser negociados entre os atores envolvidos no processo de identificação, mas não são uma característica estática ou acabada" (MOGONE, 2001, p.19).

As pesquisas que abordam o desenvolvimento e a construção da identidade docente são relativamente recentes no Brasil, especialmente as que contemplam o campo das Ciências da Natureza (PASSOS; PINO, 2016; PIRES; GONÇALVES, 2016; CAMBRAIA; ZANON, 2018). Isso evidencia que, nos últimos tempos, há uma tendência em enfatizar o estudo da vida e da pessoa do professor também desta área do conhecimento, de modo a colocar também os professores da área de Ciências da Natureza no centro das discussões educativas e dos problemas de investigação.

Segundo Santos (2008, p. 35), até a década de 1980, as produções na área de educação que abrangiam a escolarização de professores defendiam uma “[...] formação preocupada com a instrumentalização técnica dos futuros docentes 
distanciada das experiências formativas dos professores". É a partir da década de 1990 que os estudos sobre formação de professores começam a apontar para outra perspectiva teórico-metodológica de análise, envolvendo o cotidiano pedagógico e também as trajetórias de vida dos professores. Há uma dinâmica entre as dimensões profissional e pessoal, visto que o modo como o professor é enquanto pessoa implica na maneira como ele se identifica com a sua profissão a qual, consequentemente, condiciona a sua prática educativa ou, como destaca Nóvoa (1995, p.17), "A maneira como cada um de nós ensina está directamente dependente daquilo que somos como pessoa quando exercemos o ensino".

A identidade profissional diz respeito aos processos que colaboram para a definição de um conjunto de conhecimentos, valores e atitudes que conduzem à sua prática. São esses processos que compõem as maneiras como o professor reconhece e representa a sua profissão (LIBÂNEO, 2002).

Conforme Dubar (2005), determinados acontecimentos na vida social do indivíduo constituem grande importância no processo da construção de sua identidade profissional, como, por exemplo, a saída do sistema escolar (e, consequentemente, a confrontação com o mercado de trabalho), a escolha da profissão e o processo formativo. Essas ocorrências possuem fortes implicações na formação de uma identidade básica inicial, da qual se conceberá uma trajetória profissional e projeção da vida pessoal.

Ao reconhecermos a existência de uma identidade específica para o professor, estamos apontando para a responsabilidade docente frente à sua função social, de onde emergem a autonomia e o comprometimento por parte do docente com aquilo que faz. Entendemos que o professor possui uma função social que extrapola os muros da escola, visto que ele possui as mais diferentes relações no ambiente escolar, seja com colegas de profissão, com alunos, ou com a comunidade escolar (que por vezes inclui os pais ou responsáveis pelos alunos). Ele, enquanto docente, é um ser político, que exerce influência ao seu redor e principalmente em seus alunos, com relação a aspectos culturais, à cidadania, bem como aos diferentes acontecimentos do mundo contemporâneo.

Do mesmo modo que outras profissões, a docência dispõe de uma base comum de conhecimentos, cuja aprendizagem deve ser requisito para a sua execução. Nessa perspectiva, Tardif (2010, p.39) destaca que o professor "ideal" é aquele que "[...] deve conhecer sua matéria, sua disciplina e seu programa, além de possuir conhecimentos relativos às ciências da educação e à pedagogia e desenvolver um saber prático baseado em sua experiência cotidiana com seus alunos". É durante o processo de formação que o futuro profissional começa a construir os saberes referentes à sua profissão, entretanto, essa aprendizagem não se encerra na formação inicial. A inserção na carreira e o seu desenvolvimento proporcionam condições para o desdobramento e o aperfeiçoamento de saberes relativos ao próprio local de trabalho, incluindo suas rotinas, regras e valores.

Nessa perspectiva, Tardif (2010) indica a existência de quatro tipos de saberes diferentes implicados na atividade docente:

1. Saberes da Formação Profissional: compreende o conjunto de saberes que são difundidos pelas instituições de formação de professores (seja no processo de formação inicial ou continuada); nele também se 
encontram os saberes pedagógicos (referentes, por exemplo, às técnicas e aos métodos de ensino), que abrangem as concepções advindas de reflexões sobre a prática educativa os quais, ao serem adquiridos, possibilitam o auxílio ao professor a conduzir sua prática profissional.

2. Saberes Disciplinares: são aqueles que pertencem aos diferentes campos do conhecimento, como as ciências da natureza, a linguagem, as ciências exatas etc. São administrados pela comunidade científica e o acesso a esses saberes ocorre por meio de instituições educacionais, como a universidade. Essa classe de saberes, portanto, diz respeito ao conteúdo e são divulgados sob a forma de disciplinas.

3. Saberes Curriculares: pode-se dizer que são aqueles que se apresentam em forma de programas escolares que os professores aprendem e aplicam, compreendendo "[...] os objetivos, discursos, conteúdos e métodos a partir dos quais a instituição categoriza e apresenta os saberes sociais por ela definidos e selecionados como modelos da cultura erudita" (TARDIF, 2010, p.38), isto é, questões relativas ao currículo escolar.

4. Saberes Experienciais: são aqueles que se referem aos saberes específicos, com base no trabalho cotidiano e no conhecimento do contexto em que participa, e, se desenvolve na prática da profissão. Esses saberes "[...] brotam da experiência e são por ela validados. Eles se incorporam à experiência individual e coletiva sob a forma de habitus e de habilidades, de saber-fazer e de saber-ser" (TARDIF, 2010, p.39).

A construção da identidade e os saberes docentes, portanto, compreendem o processo de formação do professor. Esse processo de formação mais abrangente é caracterizado como desenvolvimento profissional docente. Segundo Imbernón (2009), o desenvolvimento profissional docente é um conceito que expressa evolução e continuidade, pois é um processo que vai se construindo à medida que os docentes vão adquirindo experiência e, além disso, quando suas práticas (advindas de suas experiências pessoais e profissionais) puderem ser aperfeiçoadas ao longo de sua carreira.

\section{PERCURSO METODOLÓGICO}

Optamos por trabalhar com a dimensão pessoal e subjetiva, pois é ela que demarca a (re)construção de uma identidade pessoal com a docência. Dessa forma, a pesquisa assume a perspectiva qualitativa de investigação (BOGDAN; BIKLEN, 1994), pelo fato de os dados não serem passíveis de mensuração, e por se buscar a análise de suas inter-relações.

A pesquisa foi desenvolvida com quatro profissionais docentes que concluíram a graduação em Licenciatura em Ciências Biológicas em uma IES pública federal situada no interior do estado de Minas Gerais. O curso é oferecido pela instituição apenas na modalidade Licenciatura e a matriz curricular é composta por disciplinas pedagógicas e disciplinas específicas (das Ciências Biológicas) em todos os períodos e sua duração é de 8 semestres (4 anos). Para a conformação desse grupo de professores, adotou-se como critério que o participante estivesse atuando na docência. 
Para preservar a identidade dos participantes, utilizou-se a letra P para se referir a cada professor. P1 tem 22 anos, um ano de docência, e leciona como professor substituto em uma universidade pública. P2 tem 35 anos, dois anos de docência, e atua em uma escola municipal no âmbito do Ensino Médio e da Educação Profissional. P3 tem 24 anos, um ano e meio de docência, e leciona no Ensino Fundamental II e Ensino Médio, em uma instituição pública e em uma instituição privada. Por fim, P4 tem 27 anos, três anos de docência, e atua no Ensino Fundamental II em uma escola municipal. A opção pela utilização de números foi adotada visando diferenciar a fala dos professores e garantir o seu anonimato. Os quatro professores atuam em instituições escolares distintas (na mesma cidade em que se formaram, em município situado no interior do estado de Minas Gerais) e se graduaram em diferentes anos na mesma IES. Destaque-se que o protocolo desta investigação foi aprovado pelo Comitê de Ética em Pesquisa da Universidade.

Para a realização deste trabalho foram empregadas entrevistas semiestruturadas, que correspondem a uma série de perguntas abertas, feitas verbalmente em uma ordem prevista, mas na qual o entrevistador pode acrescentar perguntas de esclarecimento (LAVILLE; DIONNE, 1999). As entrevistas são utilizadas para recolher dados descritivos na linguagem do próprio participante, permitindo ao pesquisador desenvolver intuitivamente uma ideia sobre a maneira como os participantes interpretam aspectos de mundo (BOGDAN; BIKLEN, 1994). Assim, as utilizamos como instrumento na medida em que levantaram as percepções e as compreensões dos participantes a respeito de como se processou sua formação, quais saberes foram mobilizados, como aparecem em suas práticas, quais conteúdos de Biologia são considerados relevantes, entre outras questões.

A dinâmica da entrevista consistiu em a pesquisadora ler cada questão uma vez (repetindo, quando necessário) e o participante já respondia, não havendo tempo delimitado para a formulação da resposta por parte dele. Todas as entrevistas foram gravadas em áudio e posteriormente transcritas na íntegra pela pesquisadora, sem a utilização de qualquer programa de computador.

Para a análise das transcrições das entrevistas deste estudo foram utilizados elementos do processo de análise textual discursiva (ATD). Trata-se de uma abordagem de análise de informações de cunho qualitativo, visando produzir novas compreensões ${ }^{1}$ acerca dos fenômenos e discursos. A ATD encontra-se entre os extremos da análise de conteúdo e da análise de discurso. Segundo Moraes e Galiazzi (2016, p. 34)

[...] A análise textual discursiva pode ser compreendida como um processo autoorganizado de construção de compreensão em que os entendimentos emergem a partir de uma sequência recursiva de três componentes: a desconstrução dos textos do "corpus", a unitarização; o estabelecimento de relações entre os elementos unitários, a categorização; o captar emergente em que a nova compreensão é comunicada e validada.

Todo o processo da ATD volta-se para a produção do metatexto, que manifesta às novas compreensões os sentidos e significados que o pesquisador tece frente ao seu corpus de análise. A partir da unitarização e da categorização é que se constrói a estrutura básica do metatexto e se tem a emergência de uma 
compreensão renovada do todo. Nessa perspectiva, elencamos três categorias que emergiram no processo analítico para interpretar os dados.

A categoria I, intitulada "A Identidade Profissional Docente", faz o movimento de pensar a identidade a partir de aspectos como a percepção do professor, a sua formação inicial e os saberes que influenciam na construção da identidade docente. A segunda categoria, denominada “Os Saberes Docentes do Professor de Biologia”, compreende questões relativas aos saberes do professor, quais saberes ele deve ter e quais são os elementos que os formam. Por fim, a categoria III, “As Dicotomias na Formação Inicial”, compreende aspectos sobre a dicotomia entre as contribuições da formação inicial e da estrutura curricular do curso analisado e a constituição e formação da identidade profissional e dos saberes docentes do Professor de Biologia.

\section{APRESENTAC̣ÃO E INTERPRETAC̣ÃO DAS INFORMAC̣ÕES}

\section{I) A Identidade Profissional Docente}

A investigação acerca do processo de tornar-se professor pressupõe uma diversidade de perspectivas, abrangendo desde o desenvolvimento do conhecimento, o saber-fazer profissional (relacionado às preocupações docentes) e também a socialização profissional. O período de transição de aluno a professor é definido pelo crescente reconhecimento de um novo papel institucional, pela interação entre crenças, perspectivas e práticas diferentes (e às vezes conflituais), que podem implicar na formação e na transformação da identidade profissional do professor (FLORES, 2010).

Ao ser questionada sobre sua percepção enquanto futura professora durante seu percurso de formação inicial, P1 diz:

"Eu entrei na graduação renegando um pouco a questão da docência, né, talvezpplo discurso da desvalorização dos professores, mesmo eu vindo de família de professores, tendo mãe e pai professores. Só que no decorrer do curso eu me identificava com eventos de Educação, eu gostava de participar, eu gostava das discussões, mas assim, ainda não estava claro pra mim a questão de me perceber enquanto professor, eu não me via professora e às vezes tentava fugir dessa área, tentava pensar em uma coisa específica [da área da biologia], em uma coisa mais de pesquisa e tal" (Transcrição de entrevista - P1).

A fala de P1 é aderente à falta de identificação com a profissão durante o período de formação inicial. Isto é, apesar de se identificar com atividades relacionadas à área da Educação, como em alguns eventos (simpósios, congressos, encontros, etc.), que dizem respeito ao universo da docência, ${ }^{2} \mathrm{P} 1$ não conseguia se perceber enquanto professora em seu processo formativo e buscava voltar-se para a área da pesquisa em temas específicos das Ciências Biológicas, dado que a professora diz que, por não se ver enquanto docente durante o curso, buscava pensar em uma "coisa mais específica", no caso, em alguma área das Ciências Biológicas, não considerando em sua fala que a área da Educação também constitui área de pesquisa. 
Por outro lado, P3 e P4 ingressaram na graduação com a intenção de seguirem a docência e se viam enquanto professores ao longo do curso. Do mesmo modo, P2 também se percebia enquanto docente em seu processo de formação inicial, caracterizando a identificação com a profissão desde o ingresso no curso. Segundo P2, ela iniciou a graduação com a finalidade de seguir a carreira docente e, além disso, considera a docência como uma profissão capaz de ajudar pessoas, indo o docente além das atribuições escolares, sendo seu desejo ajudar e incentivar seus alunos:

“[...] eu fui me graduar pra ser professor. Eu vim de uma escola de periferia e pensei que fazer um curso técnico seria a única opção. Quando eu descobri que poderia ir mais longe, optei pela licenciatura porque eu quero ajudar de alguma forma outros alunos a acreditar que também podem ir mais longe. Dentro do curso de graduação eu por muitas vezes fiquei dividida entre as áreas de atuação profissional que ele me possibilitaria após a conclusão" (Transcrição de entrevista - P2).

Observamos que a identificação com a profissão durante a formação inicial está relacionada com a intenção do aluno em seguir a carreira docente logo nos primeiros anos da graduação ou não. Entretanto, mesmo que pretenda ser professor, não significa que sentimentos como insegurança não irão permear a formação. Em um primeiro momento, P1 negava a carreira docente, querendo seguir por caminhos da área específica da Biologia. Já ao final do curso, percebeu que se identificava mais com as áreas que se interligavam à Educação, evidenciando a aceitação e a identificação com a carreira docente.

Segundo Flores (2010), os futuros professores possuem um conjunto de ideias e de crenças acerca do ensino e do que significa ser professor, que foram sendo interiorizados no percurso de sua vida escolar. Ao contrário de futuros profissionais de outras áreas, ao ingressarem na formação inicial, os licenciandos já conhecem o contexto em que vão exercer sua profissão: as salas de aula e as escolas. O longo contato com a futura profissão, por meio da observação de seus professores, poderá afetar (em maior ou menor grau) o seu entendimento e a sua prática de ensino, tanto como alunos futuros professores, quanto professores iniciantes na carreira.

Nesse contexto, P1 destacou um episódio que aconteceu durante o estágio curricular supervisionado que contribuiu para a mudança da sua percepção enquanto docente:

"Ao final do curso teve um evento, um episódio no estágio, em que eu me preparei para dar uma aula e essa aula foi diferente pra mim, apesar de ter participado do PIBID durante muito tempo, né, já estar acostumada com o espaço escolar, com essas dinâmicas, com essa preparação de aula, e essa aula foi diferente, e foi acho que a hora que eu pensei assim: 'não, eu acho que a minha formação tá me dizendo que eu devo fazer isso'. Foi quando eu comecei a me sentir professora, naquele momento, projetar a minha imagem enquanto professora. Apesar de não me enxergar por inteiro, mas pensar na possibilidade que seja de ser professora" (Transcrição de entrevista - P1).

P1 identificou que a transformação da visão que tinha em relação a si como docente se modificou de fato durante uma experiência que vivenciou no 
estágio supervisionado, com a qual começou a se perceber enquanto professora, evidenciando a aceitação e a identificação com a carreira docente. $O$ estágio supervisionado é visto como um momento de prática durante a formação inicial. Existem muitas práticas que contradizem os princípios da integração teoria-prática e a articulação entre os contextos de formação, principalmente no que se refere à ausência de uma abordagem interdisciplinar do currículo e à separação entre universidade e escola (PACHECO; FLORES, 1999; LOBATO; DAVIS, 2019).

O Estágio Curricular Supervisionado (ECS) não é considerado apenas como um momento prático em oposição aos componentes teóricos do curso, mas como uma etapa formativa em que se supõe a existência de uma interlocução ativa entre teoria e prática (BRASIL, 2002). Desse modo, a formação dos docentes deve pautar-se pela oportunidade de aproximar o licenciando dos aspectos sócio-políticoculturais do cotidiano docente a fim de compreender o papel social da educação.

Além do estágio, P1 destaca sua experiência no Programa Institucional de Bolsas de Iniciação à Docência (PIBID), ${ }^{3}$ no qual participou durante grande parte da graduação. Esse programa foi implementado no ano de 2009, com o intuito de valorizar a docência e promover a interação entre as IES e as escolas de Educação Básica, e busca contribuir de modo significativo na formação inicial de licenciandos, pois tinham a oportunidade de vivenciar o ambiente escolar antes de concluírem a graduação.

Um dos objetivos do PIBID compreende integrar a formação inicial do professor à formação da sua identidade profissional enquanto docente, possibilitando o desenvolvimento de ações que envolviam não apenas as dinâmicas de sala de aula, mas também as questões referentes à gestão administrativa da escola (SILVA; FALCOMER; PORTO, 2018). Assim como P1, P3 e P4 também participaram do PIBID e destacaram as contribuições do programa para a sua formação, evidenciando a importância do PIBID para a construção do ser professor.

Um outro fator que buscamos mapear compreende se os egressos do curso de Licenciatura em Ciências Biológicas em questão se enxergam como professores que apresentam identidade profissional própria e de que maneira a formação inicial influenciou na construção desta identidade. P1 afirma que a sua identidade profissional é construída a partir das relações sociais com outros atores e associa as questões sobre o estereótipo do professor com aspectos de seu processo de subjetivação e das representações docentes que influenciaram na construção de sua identidade. Ressalta que a sua identidade profissional tem "projeções externas, do campo, do discurso do que é ser professor com aspectos de professores que passaram pela minha vida, mas elas foram internalizadas e significadas a partir de como eu percebo o mundo e a profissão".

Nesse sentido, a experiência, as crenças e o contexto em que se realiza a atividade docente são fatores significativos no processo de tornar-se professor. Dessa forma, se a experiência, as disposições e as crenças pessoais se configuram como elementos determinantes no modo com que os professores pensam e agem no exercício docente, o contexto de trabalho também pode ser considerado como um elemento importante no posicionamento dos professores frente à profissão.

Ao exemplificar que sua visão de um "bom professor" era de um professor rígido e autoritário, P1 incorporou essas características em sua identidade docente 
no período inicial de sua carreira. Isso evidencia que os modelos de professores têm um papel fundamental na construção dos docentes que estão em formação (licenciandos, por exemplo). Esses professores-modelo podem influenciar até mesmo a escolha pela profissão docente, como relatou $\mathrm{P} 3$, ao relembrar um de seus professores do cursinho:

"[...] eu tive um Professor de Biologia es-pe-ta-cu-lar no cursinho, sabe, [...] então juntou aquele meu afastamento da área de exatas e o tanto que eu passei a gostar de Biologia no cursinho, o professor dava aulas muito boas, e não era um professor que inventava muita coisa, a aula dele era 'tradicionalzona', só que era tanto conhecimento que tinha ali...” (Transcrição de entrevista - P3).

Segundo Tardif (2010), fatores que influenciam na escolha pela profissão docente englobam antigos professores que marcaram positivamente a trajetória de vida do indivíduo, bem como experiências escolares positivas compartilhadas com os colegas ou no processo de ensino e aprendizagem. Esses modelos ou ideais de professores podem tornar-se produtos relacionados à identidade e instrumentos de afirmação de um determinado grupo (docente, nesse caso), estabelecendo uma organização acerca da compreensão do espaço social em conveniência com as pretensões identitárias de cada um (DESCHAMP; MOLINER, 2009).

\section{II) Os Saberes Docentes do Professor de Biologia}

O professor, no decorrer de sua vida profissional, desenvolve diferentes saberes para atuar em sala de aula. Ao partir do pressuposto de Tardif (2002), de que o saber dos professores é um vasto campo do conhecimento e que é originado a partir de fontes diversas e em vários momentos de sua vida, destacamos que os conhecimentos que os professores utilizam e necessitam não se findam apenas na formação acadêmica e na experiência prática. Isto é, o professor pode utilizar conhecimentos originados de seu meio familiar, de seu ambiente cultural, de sua história de vida, da aprendizagem na escola, na universidade, e também de sua prática em sala de aula, por isso, os saberes são caracterizados como plurais e heterogêneos (TARDIF, 2002).

Ao ser questionada sobre quais saberes o Professor de Biologia deve ter, P1 destaca que é imprescindível o professor saber o conteúdo (compreendendo os saberes disciplinares proposto por Tardif (2002), não somente saber o que se vai ensinar, mas saber como transpor esse conteúdo e estabelecer relações/ conexões com o mundo, de forma que seja significativo para o aluno, aproximando o conteúdo da realidade:

"É imprescindivel que ele saiba o conteúdo. Mas ele não deve saber só o conteúdo, tem a forma de transpor esse conteúdo, pra que seja significativo para o aluno, perceber a sala, perceber o contexto, perceber todas as influências externas que estão permeando ali essa aula e a disciplina de Ciências e Biologia. Então, fazer conexões com o mundo, né, tražer uma perspectiva de mundo nessa prática, pra esses alunos" (Transcrição de entrevista - P1). 
E, ainda, P1 acredita que esses são os saberes que o professor deve ter porque ele não está ali somente para explicar fenômenos ou conceitos científicos, ele está ali para "formar cidadãos [...] que se dá na interação desses saberes científicos com outros saberes, constituídos nas vivências dos alunos, do professor, dentro de um determinado contexto". Assim, P1 ressalta a importância do docente na formação do aluno enquanto cidadão, das vivências em diálogo com os saberes que vão além dos conteúdos a serem ensinados.

Além disso, P1 acrescenta que os saberes desse professor são constituídos a partir da articulação dos saberes específicos e dos saberes curriculares com as representações acerca de como esse professor percebe tais saberes na sua formação (seja ela inicial ou continuada), evidenciando que os saberes do Professor de Biologia são caracterizados pelo vínculo entre os saberes específicos e os saberes curriculares. Em contrapartida, P2 aponta que os saberes do Professor de Biologia estão sob um tripé composto pelo saber didático, o saber pedagógico e o saber social. O saber social é "aquele saber que ele mesmo construiu em sua trajetória de vida além da academia, porque ele não vai conseguir usar os outros dois saberes se não tiver construído a sua identidade, é um círculo vicioso". O professor acrescenta que no centro desse círculo "estão os conhecimentos específicos, sempre perpassados pela formação social do profissional, assim como a sua habilidade de utilizar-se da Didática e Pedagogia, antes de alcançar o aluno".

O participante $\mathrm{P} 1$, ao mencionar os saberes específicos, os relaciona com os saberes disciplinares, os quais, segundo Tardif (2002), são os saberes referentes ao conteúdo a ser ensinado, transmitido pela universidade nos diversos campos do conhecimento. Da mesma forma, P2 afirma que os conhecimentos específicos se encontram no centro da formação docente, de modo que os saberes relacionados à profissão também estão nesse centro. De acordo com P1, o saber das disciplinas também é articulado com as representações de como o professor (em formação inicial ou continuada) percebe os saberes curriculares e específicos na docência. Outro saber que aparece na fala dos professores, entretanto indiretamente, é o saber curricular, que está relacionado à organização e ao planejamento da disciplina, além de compreenderem questões relativas ao currículo escolar (TARDIF, 2002).

De acordo com P2, o Professor de Biologia deve possuir o que chama de saber didático, que diz respeito aos preceitos científicos/específicos que orientam a atividade docente de modo a torná-la mais eficiente, o que é ressaltado também por P1, que destaca a importância de o professor saber o conteúdo que irá ensinar, mas não se restringir a apenas saber o conteúdo, mas também atentar-se a como vai transpor esse conteúdo para o aluno, remetendo às técnicas que são ou que podem ser utilizadas em sala de aula. Esses saberes abordados pelas professoras vão ao encontro dos saberes da formação profissional propostos por Tardif (2002), pois abrangem a compreensão do que significa ensinar determinada matéria, o que é necessário para esse ensino (as técnicas, por exemplo) e os métodos de ensino (saber fazer), que podem ser aprendidos durante o processo de formação inicial, de formação continuada ou na prática docente.

Além disso, P1 ressalta a importância de o professor perceber o contexto, o ambiente em que está inserido, perceber a sala, os alunos, perceber o mundo fora da escola, as situações, os acontecimentos que tangenciam o momento atual, 
possibilitando realizar aproximações do conteúdo com a realidade dos alunos ou com situações que estejam próximas ao contexto deles, podendo utilizar determinado acontecimento para explicar um processo ou um fenômeno. Esses pontos levantados por P1 são passíveis de serem associados com os saberes da experiência ou saberes experenciais (TARDIF, 2002), que são os conhecimentos / saberes produzidos pelos próprios professores durante a sua vivência na profissão e no contexto educacional, de modo a possibilitar um processo individual de aprendizagem da profissão, no sentido de trazer aspectos para a reflexão sobre a importância da experiência prática na constituição do docente enquanto profissional. Além disso, P1 ressalta a função social do docente: o professor forma cidadãos, ele tem o papel de formar sujeitos críticos, capazes de compreender os processos que regem a nossa sociedade, compreender o contexto no qual estamos inseridos, etc.

Nessa perspectiva, P3 também identifica como um dos saberes dos Professores de Biologia ter uma boa fundamentação teórica revelando, assim, a importância de o professor saber o conteúdo, o que vai ao encontro dos Saberes Disciplinares, propostos por Tardif (2002). Em seguida, ao destacar a importância de se ter conhecimento da componente didática, é possível identificar na fala aspectos dos Saberes da Formação Profissional (TARDIF, 2002), os quais compreendem o conjunto de saberes que são difundidos pelas instituições de formação de professores (seja no processo de formação inicial ou continuada); nele também se encontram os saberes pedagógicos (referentes, por exemplo, às técnicas e aos métodos de ensino), que abrangem as concepções advindas de reflexões sobre a prática educativa os quais, ao serem adquiridos, possibilitam o auxílio ao professor a conduzir sua prática profissional.

Da mesma forma, P4 evidencia a importância de o professor saber o conteúdo - dialogando com os saberes disciplinares de Tardif (2002), mas não apenas, de relacioná-lo com as atualidades, de saber onde aquilo que o aluno está aprendendo em sala de aula está inserido (da mesma forma como P1 destacou a importância de o professor saber estabelecer relações entre o conteúdo e o contexto do aluno), evidenciando os saberes experienciais (TARDIF, 2002), e traz um exemplo prático para esta reflexão, na área de Microbiologia:

\footnotetext{
“[...] quando a gente tem Microbiologia na faculdade, a gente estuda lá os microrganismos se desenvolvendo, de contaminação e tudo o mais, aí você ensina uma divisão binária, lá pros alunos, das bactérias... Ah, beleza! Quando você abre um pote de conserva, a conserva tem validade por anos enquanto ela tá fechada, depois que você abriu o pote, abriu a tampa e pegou um pepino ou alguma coisa de lá de dentro, ela foi exposta ao ar e foi contaminada por cepas de bactérias, por esporos de fungos e tudo o mais. Você fechou ela novamente e colocou na geladeira, se você olhar a validade, agora são quatro dias, não é mais um período longo" (Transcrição de entrevista - P4).
}

Ao trazer esse exemplo, P4 destaca a possibilidade de o professor explorar situações do cotidiano do aluno para introduzir determinado conteúdo. Utilizar fenômenos cotidianos associados a conhecimentos científicos teóricos nas aulas podem torná-los mais compreensíveis para os alunos (WARTHA; SILVA; BEJARANO, 2013). No entanto, nem sempre a formação inicial dá subsídios para 
construir o repertório de mundo dos professores, de modo que é relevante que o docente seja capaz de contextualizar situações cotidianas para aguçar a curiosidade do aluno. Nesse sentido, contextualizar é uma estratégia essencial ao professor para que ocorra a construção do conhecimento junto aos seus alunos (WARTHA; SILVA; BEJARANO, 2013).

\section{III) As Dicotomias na Formação Inicial}

A formação de professores se concebe a partir de diversos momentos de troca, de compartilhamento de saberes e conhecimentos e, assim, o currículo se manifesta de modo crítico, rompendo com a lógica documental, pois adquire significado no cenário das ações educativas. O currículo envolve saber, poder e identidade, representando dessa forma um território de lutas e de poder, onde estão embutidos pensamentos e posicionamentos (SILVA, 2007). Além disso, o currículo caracteriza uma fonte de conhecimento, por ser elaborado e pensado pelos sujeitos que fazem parte do cotidiano das instituições de ensino, difundindo "visões sociais particulares e interessadas" (MOREIRA; SILVA, 2013, p.14), transparecendo suas manifestações de poder. Em vista disso, o currículo se torna um espaço dinâmico de construção dos conhecimentos e dos saberes expressivos para o processo formativo dos professores, constituindo uma proposta educacional de cada instituição de ensino.

Ao discutir se a estrutura curricular do curso em que se graduou propiciou contribuições com relação à sua identidade profissional enquanto docente, P1 afirmou que contribuiu para a identidade profissional em uma perspectiva técnica, de modo que a ênfase se dava nas disciplinas específicas de Biologia (mesmo sendo um curso que contempla somente a modalidade licenciatura - a instituição não oferta a modalidade bacharelado). Dessa forma, de acordo com Pereira (2000), apesar de a futura atuação ser na docência, o aluno se forma tendo em mente o ideal de formação de pesquisadores em Ciências Biológicas. Essa ênfase na pesquisa se reflete, por exemplo, em falas anteriores de P1 e P2, nas quais explanaram que em determinado momento do curso pensaram em seguir outra área que não a docência.

No Brasil, ainda há a ideia de que a docência nas instituições de ensino superior tem o domínio do conhecimento específico e a excelência na pesquisa como características suficientes para a qualidade (PRATA-LINHARES; PIMENTA; GONÇALLO, 2017). Essa perspectiva compreende o modelo da racionalidade técnica, que está presente em grande parte dos programas de formação de professores, ocasionando uma separação entre os elementos da prática profissional e os teóricos da formação - podendo resultar em uma desarticulação na formação dos professores (LIBÂNEO, 2015). Esse cenário apresenta a formação docente em uma dicotomia: da prática (nas instituições escolares) e da teoria (nas universidades - enfatizando competências e habilidades específicas).

Além disso, P1 revela a dicotomia teoria-prática existente no curso, em que o aluno só 'se sente’ professor quando está no estágio supervisionado: “[...] parece que a gente é professor só na hora que a gente tá lá no estágio, e mais ou menos, porque a sala não é sua. Parece um teatro de ser professor e quando você tá nas questões específicas, você é um aluno, você quer ser o mais aplicado e passar por aquilo logo, você não vai pensar em como ensinar aquilo, como transpor 
aquilo, como aproximar aquilo do que você está estudando naquele momento". Segundo Pimenta (1999), a desarticulação do Estágio Curricular Supervisionado se relaciona à ausência de relações entre 'o que ensinar', 'como ensinar' e 'a quem ensinar', o que provoca uma dicotomia entre a teoria e a prática.

Sob o ponto de vista de P2, a formação inicial também proporcionou contribuições para a construção de sua identidade docente e, da mesma forma que P1, afirma que as disciplinas do curso são mais técnicas, voltadas para um curso de Ciências Biológicas na modalidade bacharelado, embora o curso de Ciências Biológicas na universidade pesquisada seja ofertado apenas na modalidade licenciatura:

\begin{abstract}
"A licenciatura que eu cursei, embora na prática seja bastante questionada, por causa das dificuldades de adaptação universitárias diante do que ainda chamamos de grade, na teoria ela é muito bonita, ela foi muito específica, uma parte pedagógica muito boa e depois uma parte mais técnica, mais voltada para o bacharelado nos anos finais da graduação. Só que, infelizmente, estamos presos à atuação específica de cada profissional. Eu acho que esse é o maior problema da docência, porque o projeto no papel é muito bonito, mas quando ele passa a ser executado, ele ganha muitas falhas humanas, e isso vai sendo impregnado na percepção que a gente tem. O curso acaba, pelo componente humano, direcionado mais para o bacharelado e a pessoa acaba se esquecendo que foi lá para ser um docente. Quanto às contribuições, eu pude aproveitar bastante todas as discussões pedagógicas e didáticas pra poder trazer comigo, pra minha prática, e até mesmo pra me direcionar na pós-graduação. Se não fosse a estrutura do curso de licenciatura, que me proporcionou tantos debates, tantos embates sobre as questões educativas, en talvez tivesse me direcionado para uma outra parte da atuação da Biologia" (Transcrição de entrevista - P2).
\end{abstract}

Ao fazer referência que 'o projeto no papel é muito bonito', P2 estabelece uma conexão com o Projeto Pedagógico de Curso (PPC), que em muitos momentos frisa a questão da formação do aluno enquanto professor (como no perfil do egresso, nos objetivos do curso e nas habilidades e competências) quando, na prática, os aspectos específicos do curso, voltados para a técnica, são colocados em evidência. Isso pode fazer com que se configure uma fragmentação na formação do aluno, pois nem sempre o que está documentado e orientado no PPC é seguido no desenvolvimento das disciplinas do curso. Destaque-se que os quatro participantes deste estudo tiveram seus itinerários formativos construídos a partir de um PPC fundamentado nas Diretrizes Curriculares Nacionais de Formação de Professores do ano de 2002 (BRASIL, 2002), portanto que ainda não contavam com 400 horas de Prática como Componente Curricular (PCC), como atualizado nas Diretrizes promulgadas no ano de 2015 (BRASIL, 2015) o que pode, de alguma forma, justificar os resultados alcançados com as falas trazidas na entrevista com P2. O modelo que abrange a instrumentalização técnica contribui para uma crise de identidade dos professores, visto que uma prática consolidada em padrões técnicos contribui para negligenciar a perspectiva pessoal da profissão docente, ressaltando que o professor não é um reprodutor de normas e técnicas, "[...] o professor é uma pessoa. E uma parte muito importante dessa pessoa é o professor [...]" (NÓVOA, 2000, p.15). Além disso, P2 ressalta que as disciplinas pedagógicas do curso contribuíram 
significativamente na construção da sua identidade enquanto profissional, pois a partir das discussões realizadas em aulas, pode significar as questões educativas e posteriormente direcioná-la para a área da Educação.

Entretanto, a fala de P2 é contraditória. No início evidencia que o curso começa com uma característica voltada mais para a área didático-pedagógica, que não perdura até o fim, visto que nos anos finais da graduação volta-se para uma parte mais técnica, relacionada às características da modalidade bacharelado e, em um segundo momento, a professora chega a elogiar a estrutura do curso (que antes criticou) e afirma que, se não fosse este modelo de estruturação, ela poderia ter se direcionado para outra área de atuação dentro do campo da Biologia. De acordo com Santos e Mororó (2019), a origem das licenciaturas está mais atrelada às exigências da regulamentação da atividade docente do que à criação de um curso para formar professores visto que, anteriormente, para adquirir a licença, o bacharelado era exigido como pré-requisito.

As licenciaturas só começam a ganhar sua própria identidade depois de 1960, com a publicação da Lei de Diretrizes e Bases da Educação Nacional, em que se extingue o modelo de licenciatura associado ao bacharelado. Porém, o marco para a criação dos cursos de licenciatura só ocorre em 1968, com a reforma das universidades e a criação de departamentos específicos, desvinculando as licenciaturas dos bacharelados (SANTOS; MORORÓ, 2019). Ao contrário, esse mesmo processo acelerou a formação de professores em licenciaturas curtas, que acabou priorizando os conhecimentos específicos em vez dos conhecimentos pedagógicos, contribuindo para a precarização da formação dos professores (SANTOS; MORORÓ, 2019).

O participante $\mathrm{P} 3$ ingressou na faculdade visando seguir a docência e identificou que as disciplinas que cursou, tanto as pedagógicas, como as da área específica da Biologia, contribuíram para a sua identidade enquanto professor e, além disso:

“[...] via um pouquinho de preconceito ali de professores das pedagógicas e professores de específicas e, assim, apesar de muitos professores de pedagógicas acharem que não, eu achei que nossos professores das áreas especificas tinham, sim, uma preocupação com o ensino, $[. .$.$] com formas diversas de ensinar, fizemos muitos trabalhos relacionados$ a isso, a própria longa temática de Estudos e Desenvolvimento de Projetos, né, você tinha ali professores da área especifica toda semana, de uma certa forma te criticando, em cima de um projeto que você vinha desenvolvendo, como aquilo poderia ser produtivo, em uma situação de aprendizado, então a estrutura curricular foi importante sim, mas eu ainda volto a falar da grande contribuição que o PIBID teve pra mim... a vivência do PIBID contribuiu muito, somou bastante à experiência da graduação" (Transcrição de entrevista - P3).

Em sua fala, P3 ressalta novamente a importância que o PIBID teve em sua formação, de modo que complementou as experiências vivenciadas durante a formação inicial e evidencia que o professor é um indivíduo que aprende ao estar imerso em situações concretas de ensino (MARCELO, 2009).

Ainda sobre as disciplinas do curso, P3 evidenciou que determinadas falas tinham uma preocupação em formar o professor, mas não todas, de forma que 
destacou como principais influências nesse processo o perfil do professor que ministra a disciplina e a carga horária:

\begin{abstract}
“[...] vou destacar dois pontos: o perfil do professor, então aquele professor que tem a preocupação com a formação docente, você vê que ele o tempo todo insere, mesmo em suas aulas teóricas, ele consegue inserir isso num contexto educativo, e o outro ponto é muitas vezes a pequena carga horária pra um vasto conteúdo teórico. Então acho que fica um desafio pro professor do terceiro grau, antigo terceiro grau, né, ensino superior, muitas vezes há uma carga horaria muito reduzida e ainda tem que colocar isso em um contexto de formação de professores, eu acho que é um desafio, que alguns conseguiram cumprir isso muito bem [...]. Já outros professores se atém apenas ao conteúdo teórico, então 'passe na minha matéria, talvez você vai ser um pesquisador da área biológica, talvez você vai ser um professor, isso é problema seu"' (Transcrição de entrevista - P3).
\end{abstract}

Dentre as responsabilidades docentes está o ensinar, que presume dois aspectos: um intencional e um de resultados. A docência é um trabalho que demanda a compreensão da área específica que será ensinada, bem como seu significado social. O professor precisa entender questões sobre o currículo, planejamento, definir um método de ensino de acordo com o seu perfil, determinar critérios de avaliação, dentre outros (GAETA; MASET'TO, 2013). Por outro lado, o estudo de Melo e Naves (2012) aponta que na maioria das universidades as atividades relativas à pesquisa são priorizadas e, nas discussões entre os professores, os artigos que foram publicados e os projetos que foram aprovados são assuntos presentes, mas não há referência a metodologias ou formas de aprendizagens dos alunos. Isso pode ocorrer devido à menor valorização das atividades de ensino no meio acadêmico ou mesmo pela não existência de espaços institucionais para o desenvolvimento profissional docente, o que pode tornar compreensível que os professores do ensino superior se mostrem menos atentos às questões pedagógicas (PRATA-LINHARES; PIMENTA; GONÇALLO, 2017), como podemos verificar a partir da fala de P3, que evidencia dois perfis de professores do curso: aqueles que possuem uma preocupação com a formação docente, buscando em suas aulas priorizar o contexto educativo, e aqueles que não se atentam para a formação docente e acabam por priorizar o conteúdo teórico.

Segundo Dubar (2005), um aspecto significativo no processo de construção da identidade profissional docente corresponde à formação, o que vai ao encontro das falas dos professores, pois todos ressaltaram a contribuição da formação inicial para a constituição/construção das suas identidades enquanto professores (e dos seus saberes). Para o autor a formação proporciona a integração de saberes fundamentais no fortalecimento da relação com a profissão, no caso, a docência. Esses saberes não são relativos apenas aos conhecimentos desenvolvidos, reconhecidos socialmente e consequentemente transmitidos aos professores, mas também a outros tipos de saberes que podem ser incorporados em outros ambientes de formação ou mesmo no próprio local de trabalho. Cabe ressaltar que identidade e saberes não se excluem, ao contrário, são elementos que se complementam. 


\section{CONSIDERACִ̃̃ES FINAIS}

O entendimento dos processos formativos vividos por Professores de Biologia e a definição dos conhecimentos profissionais que estão na base da atuação docente e da identidade dos professores aparecem como temas centrais em estudos sobre formação docente, especialmente a partir da década de 1980. Compreender a forma como o docente constrói sua identidade profissional implica em compreender também como ele estabelece suas relações com a profissão, como se constitui no percurso profissional o ser professor, revelando suas maneiras de ser e de tornar-se professor. Assim, esse estudo teve como objetivo principal compreender, a partir das percepções de quatro egressos do curso de Licenciatura em Ciências Biológicas oferecido por uma IES pública, como se constitui a identidade profissional docente em relação aos saberes construídos pelos professores de Biologia iniciantes. Há que se ter em consideração que as considerações aqui pontuadas, portanto, circunscrevem-se aos quatro egressos participantes da investigação.

Foi possível observar que a identificação com a profissão durante a formação inicial está relacionada com a intenção do aluno em seguir a carreira docente logo nos primeiros anos do curso de graduação ou não, de acordo com as falas dos participantes P2, P3 e P4.

No entanto, mesmo que o estudante pretenda ser professor, não significa que sentimentos como insegurança não farão parte da sua formação. Um dos elementos que compõe a identidade docente e faz parte de seu processo construtivo diz respeito às experiências anteriores à graduação, chamadas também de "aprendizagens pela observação". As experiências dos professores enquanto alunos influenciam o seu "tornar-se" professor, é nesse contexto que surge a afirmativa de que o professor ensina como viu ensinar. Isto é, a partir das experiências boas e ruins com seus professores anteriores é que o futuro professor internaliza o que ele quer ou não quer ser, conforme apontam P1 e P3.

Assim, estas experiências são fundamentais na socialização dos professores (e na construção de sua identidade) e, por isso, é importante criar espaços de diálogo na formação inicial para discutir as crenças e as teorias implícitas que os alunos trazem, com a finalidade de potencializar uma reflexão e estabelecer questionamentos sobre o processo de tornar-se professor.

Além disso é possível evidenciar, a partir do presente trabalho, a importância do Estágio Curricular Supervisionado e de programas de iniciação à docência como o PIBID (e, posteriormente, a Residência Pedagógica) na formação do professor, pois proporcionam um espaço para aliar teoria e prática no contexto escolar, de modo a possibilitar ao futuro professor a vivência do ambiente de trabalho docente (e observar como funciona - ou não - na prática o que ele aprende em sala de aula na universidade), o que foi pontuado por P1, P3 e P4. Os saberes docentes são elementos que também fazem parte da identidade do professor. Todos os participantes evidenciaram os saberes que vão ao encontro dos saberes docentes propostos por Tardif (2002): os saberes disciplinares (evidenciando a importância do professor saber o conteúdo); os saberes curriculares (destacando as questões relativas ao currículo escolar); o saber didático (compreendendo os saberes da 
formação profissional) e os saberes experienciais (evidenciando a necessidade de o professor perceber o contexto, utilizar determinado acontecimento para explicar um processo ou um fenômeno nas Ciências ou na Biologia, de saber onde aquilo que o aluno está aprendendo em sala de aula está inserido no cotidiano).

Os pontos evidenciados a partir dos dados levantados e discutidos aqui são contribuições para a pesquisa em Ensino de Biologia, bem como para a pesquisa em Formação de Professores de Biologia. No entanto, apesar de apresentar informações que contribuem para a compreensão da identidade docente de Professores de Biologia iniciantes e a sua constituição, há ainda um longo caminho a ser percorrido a fim de promover e ampliar espaços de diálogo acerca da temática, o que enseja a realização de novas pesquisas em continuidade a esta.

\section{REFERÊNCIAS}

BOGDAN, R.; BIKLEN, S. Investigação Qualitativa em educação: uma introdução à teoria e aos métodos. $1^{\text {a }}$ ed. Porto: Porto Editora, 1994.

BRASIL. Resolução CNE/CP 01/2002, de 18 de fevereiro de 2002a. Institui as diretrizes curriculares nacionais para a formação de professores da educação básica, em nível superior, curso de licenciatura, graduação plena. Diário Oficial da União, Brasília, 09 abr. 2002a. Seção 1, p. 8.

BRASIL. Conselho Nacional de Educação. Define as Diretrizes Curriculares Nacionais para a formação inicial em nível superior (cursos de licenciatura, cursos de formação pedagógica para graduados e cursos de segunda licenciatura) e para a formação continuada. Resolução CNE/CP n. 02/2015, de $1^{\circ}$ de julho de 2015. Brasília, Diário Oficial [da] República Federativa do Brasil, seção 1, n. 124, p. 8-12, 02 de julho de 2015. Disponível em: < http://pesquisa.in.gov.br/imprensa/jsp/visualiza/ index.jsp?data $=02 / 07 / 2015 \&$ kornal $=1 \&$ pagina $=8 \&$ totalArquivos $=72>$. Acesso em: 30 mar. 2020.

BROWN, A.; STARKEY, K. Organizational identity and learning: a psycodynamic perspective. The Academy of Management Review, v. 25, n.1, p.102-118, 2000.

CAMBRAIA, A. C.; ZANON, L. B. Desenvolvimento profissional docente numa licenciatura: interlocuções sobre o projeto integrador. Revista Brasileira de Educação, v. 23, p. 1-24, jul. 2018. Disponível em <http://dx.doi.org/10.1590/s1413-24782018230043>. Acesso em; 30 mar. 2020.

CIAMPA, A. C. Identidade humana como metamorfose: a questão da família e do trabalho e a crise de sentido do mundo moderno. Interações, São Paulo, v. 3, n.6, p.87-101, 1998.

DESCHAMPS, J. C.; MOLINER, P. A identidade em Psicologia Social: dos processos identitários às representações sociais. Petrópolis: Vozes, 2009.

DUBAR, C. A socialização: construção das identidades sociais e profissionais. São Paulo: Martins Fontes, 2005.

FLORES, M. A. Algumas reflexões em torno da formação inicial de professores. Educação, Porto Alegre, v.33, n.3, p.182-188, 2010.

GAETA, C.; MASET'TO, M. O professor iniciante no ensino superior: aprender, atuar e inovar. São Paulo: SENAC São Paulo, 2013.

GERALDI, J. W. A aula como acontecimento. In: GERALDI, J. W. A aula como acontecimento. Barequeçaba: Pedro \& João Editores, 2010. Cap. 8. p. 81-101. 
IMBERNÓN, F. Formação Docente e Profissional: formar-se para a mudança e a incerteza, Cortez: São Paulo, 2009.

LAVILlE, C.; DIONNE, J. A construção do saber: manual de metodologia de pesquisa em ciências humanas. Belo Horizonte (MG): UFMG, 1999.

LIBÂNEO, J. C. Adeus professor, adeus professora? Novas exigências educativas e profissão docente. $6^{\mathrm{a}}$ Ed. São Paulo: Cortez, 2002.

LIBÂNEO, J. C. Formação de professores e didática para o desenvolvimento humano. Revista Educação e Realidade, Porto Alegre, v. 40, n. 2, p. 629-650, abr.-jun. 2015.

LOBATO, V. S.; DAVIS, C. L. F. Saberes e profissionalidade de egressos do curso de Pedagogia das Águas: a formação inicial em foco. Educ. rev., vol.35, n.78, p.167-185, dez. 2019. Disponível em <https://doi.org/10.1590/0104-4060.67101>. Acesso em: 22 mar. 2020.

MARCELO, C. A identidade docente: constantes e desafios. Revista Brasileira de Pesquisa sobre Formação Docente, Belo Horizonte, v.01, n. 01, p. 109-131, 2009.

MELO, F. G.; NAVES, M. L. P. (org.). Docência na universidade: em foco os formadores de professores. In: MELO, F. G; NAVES, P. L. M. (org.). Didática e docência universitária. Uberlândia: EDUFU, 2012, p.29-56.

MOGONE, J. A. De alunas a professoras: analisando o processo da construção inicial da docência. 2001. Dissertação (Mestrado em Educação Escolar) - Universidade Estadual Paulista "Júlio de Mesquita Filho”, Araraquara. 2001.

MORAES, R.; GALIAZZI, M. C. Análise Textual Discursiva. $3^{\mathrm{a}}$ ed. Rev. Amp. Ijuí: Editora Unijuí, 2016.

MOREIRA, A. F. B.; SILVA, T. T. Sociologia e teoria crítica do currículo: uma introdução. In: A. F. B. MOREIRA; T. T. SILVA. (org.). Currículo, cultura e sociedade. 12a ed. São Paulo: Cortez, 2013.

NÓVOA, A. Os professores e a sua formação. 2a ed. Lisboa: Dom Quixote, 1995.

NÓVOA, A. (org.). Vidas de Professores. $2^{\text {a }}$ ed. Porto: Porto Editora, 2000.

PACHECO, J. A.; FLORES, M. A. Formação e avaliação de professores. Porto: Porto Editora, 1999.

PASSOS, C. G.; PINO, J. C. Analisando o desenvolvimento profissional de um licenciando em Química: relações entre concepções epistemológicas e modelos didáticos. Química Nova, v. 40, n. 2, p. 219-227, set. 2016. Disponível em <http://dx.doi.org/10.21577/0100-4042.20160175>. Acesso em 30 mar. 2020.

PEREIRA, J. E. D. Formação de Professores - pesquisa, representações e poder. Belo Horizonte: Autêntica, 2000.

PIMENTA, S. G Formação de professores: Identidade e saberes da docência. In: PIMENTA, S. G. (org.). Saberes pedagógicos e atividade docente. São Paulo: Cortez, 1999.

PIRES, R.; ALVES, M. G.; GONÇALVES, T. N. R. Desenvolvimento Profissional Docente: percepções dos professores em diferentes períodos ao longo da vida. Revista Portuguesa de Pedagogia, v. 50, n. 1, p. 57-78, jan. 2016. Disponível em < https://impactum-journals.uc.pt/ rppedagogia/article/view/3865/3064>. Acesso em: 04 abr. 2020. 
PRATA-LINHARES, M.; PIMENTA, M. A. A.; GONÇALLO, R. L. A. Educação Superior no Brasil: Desafios e Expectativas dos Professores Iniciantes. Revista E-Curriculum (PUCSP), v.15, n.1, p. 615-639, 2017.

SANTOS, C. W.; MORORÓ, L. P. O desenvolvimento das licenciaturas no Brasil. Revista Histedbr On-line, v. 19, p. 1-19, jun. 2019. Disponível em <http://dx.doi.org/10.20396/rho.v19i0.8652339>. Acesso em: 25 mar. 2020.

SANTOS, S. P. F. Itinerâncias formativas: o processo de construção da identidade docente. 2008. Dissertação (Mestrado em Educação) - Universidade do Estado do Pará, Belém. 2008.

SCHAFFEL, S. L. A identidade profissional em questão. In: V. M. F. CANDAU (org.). Reinventar a escola. $5^{\text {a }}$ ed. Petrópolis: Vozes, 2007, p.102-115.

SILVA, D. M. S.; FALCOMER, V. A. S.; PORTO, F. S. As Contribuições do PIBID para o Desenvolvimento dos Saberes Docentes: a experiência da licenciatura em ciências naturais. Ensaio: Pesquisa em Educação em Ciências (Belo Horizonte), v. 20, p. 1-22, out. 2018.

SILVA, T. T. da. Documentos de identidade: uma introdução às teorias do currículo. Belo Horizonte: Autêntica, 2007.

SOUZA, J. F. Identidade profissional do docente de licenciatura em Ciências Biológicas da UFS: desvelando os significados de ser professor. 2012. Dissertação (Mestrado em Educação) Universidade Federal de Sergipe, São Cristóvão. 2012.

TARDIF, M. Saberes Docentes e Formação Profissional. Petrópolis: Editora Vozes, 2002.

TARDIF, M. Saberes Docentes e Formação Profissional. Trad. Francisco Pereira. 11 ed. Petrópolis: Editora Vozes, 2010.

WARTHA, E.J.; SILVA, E.L.; BEJARANO, N.R.R. Cotidiano e contextualização no ensino de química. Química Nova na Escola, São Paulo, v. 35, n. 2, p. 84-91, 2013.

\section{NOTAS}

1 Estas novas compreensões sobre os fenômenos e discursos da pesquisa são expressas por meio de metatextos na ATD.

2 Cabe ressaltar que a referência aos eventos na área da Educação compreenderem o universo da docência é evidente para os professores-pesquisadores (que atuam nas universidades e participam, por vezes, de simpósios, congressos, semanas acadêmicas, entre outros). Entretanto, para os professores em exercício em outras instituições, tais eventos acadêmicos podem não ser tão evidentes como pertencentes à área da docência.

3 O PIBID figurou no cenário das IES até o primeiro semestre de 2018. A partir do segundo semestre de 2018 também foi instituído o Programa de Residência Pedagógica. Este último é uma das ações que integram a Política Nacional de Formação de Professores e tem por finalidade induzir o aperfeiçoamento do Estágio Curricular Supervisionado nos cursos de licenciatura, de modo a promover a imersão do licenciando na escola de Educação Básica, a partir da segunda metade de seu curso (essa imersão deve contemplar, entre outras atividades, regências em sala de aula e intervenções pedagógicas). 
Submetido em 14/01/2020

Aprovado em 15/04/2020

Contato:

Universidade Federal do Triângulo Mineiro (UFTM)

Instituto de Ciências Exatas, Naturais e Educação (ICENE)

Av. Randolfo Borges Júnior, 1400 - Unidade III - Univerdecidade

CEP: 38064-200 - Uberaba, MG - Brasil 